\title{
Estimation of Carrying Capacity of Livestock and Poultry Based on RS and GIS: a Case in Minhou County, Fuzhou City
}

\author{
Yaxing Li ${ }^{1,2}$, Bojie Yan ${ }^{1,2 *}$, Jingjie Yan $^{3}$,Wenjiao Shi ${ }^{4,5}$ \\ ${ }^{1}$ The Academy of Digital China, Fuzhou University, Fuzhou 350002, China \\ ${ }^{2}$ Ocean College, Minjiang University, Fuzhou 350108, China \\ ${ }^{3}$ College of Telecommunications and Information Engineering, Nanjing University of Posts \\ and Telecommunications, Nanjing 210003, China \\ ${ }^{4}$ Key Laboratory of Land Surface Pattern and Simulation, Institute of Geographic Sciences \\ and Natural Resources Research, CAS, Beijing 100101, China \\ ${ }^{5}$ College of Resources and Environment, University of Chinese Academy of Sciences, \\ Beijing 100049, China
}

Received: 14 January 2020

Accepted: 20 March 2020

\begin{abstract}
To reduce the environment pollution risk from livestock and poultry breeding (LPB), it was necessary to control regional carrying capacity of livestock and poultry (CCLP).

Landsat 8 images in March and July, 2016 was used to extract cultivated land area in Minhou County by using remote sensing (RS) technology. On this basis, CCLP of Minhou County in village scale was estimated by livestock and poultry density, livestock manure nitrogen (phosphorus) load of farmland, and the alarm value of pig manure equivalent load. The results showed that the total cultivated land area in Minhou County was 27665.11 ha and had a relative error of $3.08 \%$ comparing to actual cultivated land area in Minhou County of 26838.00 ha. The results also indicated that the CCLP of Minhou County calculated by 4 index was different. Among them, the livestock and poultry density was the most stringent index, followed by the alarm value of pig manure equivalent load, livestock manure nitrogen load of farmland and livestock manure phosphorus load of farmland. Moreover, the result demonstrated that the maximum and minimum CCLP of Minhou County calculated by 4 indexes was all in Xitou village and Houcun village in Baisha Town. The results could provide a scientific basis for spatial layout of livestock and poultry breeding (LPB) and prevention of environmental pollution might be caused by LPB.
\end{abstract}

Keywords: remote sensing, cultivation land, livestock and poultry, carrying capacity

*e-mail: bnunercita@163.com 


\section{Introduction}

With rapid development of China's economy, the LPB has also been developed quickly and presented the phenomenon that the scale of LPB was not limited as long as the capacity of farmers was enough in some region [1-2]. The policy document of " $12^{\text {th }}$ Five-Year Plan for Pollution Prevention and Control in LPB" required that the total amount of livestock and poultry should be determined reasonably according to the actual situation of land conditions and environmental carrying capacity [3]. The scientific judgment of regional CCLP was the premise to reduce environmental pollution risk from LPB.

At present, the CCLP had been highly concerned by many scholars. The CCLP was mainly calculated by livestock and poultry density in national scale [4-5], livestock manure nitrogen (phosphorus) load of farmland in national scale [6], county scale [7] and town scale [8-9], the equivalent load of pig manure [10], alarm value of pig manure equivalent load [11], available forage for livestock [12-13]. In addition, Thapa [14] analyzed the carrying capacity of land resources based on total digestive nutrient demand and supply situation in Shyangja district and gained the amount of total digestive nutrient to 147,735 livestock standard units . According to the theory of nutrient balance in cultivation land, $\mathrm{Wu}$ et al. [15] determined the CCLP in Yucheng, Shandong Province and Peng and Bai [16] calculated the CCLP in Putian City, Fujian Province. Based on the theory of agricultural circular economy, Hao et al. [17] allocated quantity of livestock and poultry according to regional planting allocation and carried out the optimization of spatial allocation of LPB by using GIS technology.

In summary, different index was used to calculate CCLP in above studies. However, these studies mainly focused on calculating CCLP in different administrative scale such as national scale, province scale, city scale and county scale, while studies on town scale was weak, and studies on village scale was few. In addition, CCLP could not be calculated quickly by index such as livestock and poultry density, livestock manure nitrogen load of farmland, and alarm value of pig manure equivalent load at present due to cultivation land could not be obtained quickly. Many researchers had indicated that the RS technology could quickly extract cultivation land scientifically [18-20]. For example, $\mathrm{Xu}$ et al. [18] conducted cultivated land mapping along the Nile in Egypt from 1984 to 2015 and showed that the average overall classification accuracy of cultivated land was more than $90 \%$.

This paper extracted cultivated land of Minhou County by using RS technology based on Landsat 8 images in March and July, 2016. Then, the CCLP of Minhou County in village scale was estimated by index including livestock and poultry density, livestock manure nitrogen (phosphorus) load of farmland, and the alarm value of pig manure equivalent load respectively.
Finally, CCLP estimated by different index was compare.

\section{Material and Methods}

\author{
Study Area
}

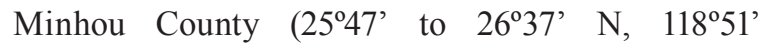
to $119^{\circ} 25^{\prime} \mathrm{E}$ ) with a total area of $2136 \mathrm{~km}^{2}$ and a population of 648,000 located in the southwest of Fuzhou City. The territory of Minhou County belonged to the central subtropical monsoon climate zone, with an average annual temperature of $14.8-19.5^{\circ} \mathrm{C}$ and annual precipitation of $1200-2100 \mathrm{~mm}$. The statistic of livestock and poultry and planting area of main crops were gained from Yearbook of Minhou in 2017. In 2016, the planting area of main crops in Minhou County mainly included $6,640.53$ ha rice, 486.8 ha maize,1,393.2 ha sweet potato, $1,152.8$ ha soybean, 684.67 ha peanut, 15 ha rapeseed, 146.46 ha sugarcane, 29,098.6 ha vegetable, 920.1 ha melons and fruits. The basic situation of livestock and poultry breeding in Minhou County mainly included 356610 pigs, 5758 beef cattle, 1689 cows, 1653 draft cattle, 37914 goats, 132369 rabbits, 324677 layers, 968278 broilers and 1485308 ducks. Among them, the number of cow, beef cattle, draft cattle, goat and layer was counted in stock, while pig and rabbits, broilers and ducks was counted in slaughter.

\section{Data Collecting and Processing}

The digital administrative map of Minhou County in village scale was vectored based on the administrative map of Minhou County by using ArcGIS 10.2 software. The Landsat8 images of Minhou County in March and July, 2016 were gained from the geospatial data cloud website(http://www.gscloud.cn/). At first the Landsat8 images of Minhou County in March and July, 2016 were processed by radiation calibration, atmospheric correction and fusion in ENVI5.1 software. Then, the fused images were mosaicked and cut by using digital administrative map of Minhou County. Afterwards, the combination of $6,5,2$ bands was adopted because the combination of $6,5,2$ bands could better reflect the information of cultivated land. Finally, the combination results were processed by Photographic Stretch to prepare for establishing visual interpretation signs.

\section{Extraction of Cultivated Land in Minhou County Based on Landsat8 Images}

\section{The Supervised Classification Method}

Supervised classification method was used to extract cultivated land in Minhou County based on Landsat8 images in this paper. Firstly, the region of interest (ROI) was selected manually. Secondly, the discriminant 
function was established by the computer according to the selected ROI [21]. Thirdly, the discriminant function was used to classify other non-classified pixels, which was also called training site method [22-23]. Finally, the separability test of ROI should be made. If the ROI was not qualified, the ROI should be checked one by one or re-established. Supervised classification method included maximum likelihood, minimum distance method, mahalanobis distance, etc. [24-25]. The maximum likelihood was adopted in this paper.

\section{Classification Precision Evaluation Method}

Kappa coefficient, artificial interpretation and area relative error were used to evaluate the classification precision of cultivated land extraction in this paper.

- Kappa coefficient

Kappa coefficient is often used to evaluate the classification precision of remote sensing images. The Kappa coefficient can be calculated as follows [26-27]:

$$
K=\frac{P_{A}-P_{B}}{1-P_{B}}
$$

...where $P_{A}$ is the sum of diagonal grids in a matrix, $P_{B}$ is the sum of products for the sum of each row and the sum of corresponding columns.

- Manual interpretation

The sample points of cultivated land with uniform distribution were randomly selected by manual interpretation based on Google image. Then the accuracy of the extracted cultivated land was tested by the proportion of the sample points to the extracted cultivated land.

- Area relative error

Firstly, the grid data of cultivated land were gained by ENVI5.1 software and ArcGIS 10.2 software. Secondly, the total number of grid data of cultivated land in Minhou County was calculated by using statistical tools. Finally, the cultivated land area in Minhou County could be obtained by multiplying the grid data of all cultivated land by the actual size expressed by each grid. The size of each grid was $15 \mathrm{~m} \times 15 \mathrm{~m}$.

\section{Calculation of CCLP}

The index including livestock and poultry density, livestock manure nitrogen (phosphorus) load of farmland, and the alarm value of pig manure equivalent load were selected to calculate CCLP in this paper.

- The CCLP estimated by livestock and poultry density can be calculated as follows [8-9]:

$$
C_{\text {density }}=A_{\text {pig }} \times \sum_{i=0}^{n}\left(F_{\text {density }} \times S_{i}\right)
$$

...where $C_{\text {density }}$ is CCLP estimated by livestock and poultry density; $F_{\text {density }}$ is limited value of livestock and poultry and determined as 2 AU/ha stipulated by $\mathrm{EU}, \mathrm{AU} / \mathrm{ha}$ [28]; $S_{i}$ is cultivated land area, ha; $A_{p i g}$ is conversion coefficient of livestock and poultry and determined as 9.09 from previous studies [28-29], ha; $n$ is number of cultivated land.

- The CCLP estimated by livestock manure nitrogen (phosphorus) load of farmland can be calculated as follows: $[8,9]$

$$
C_{\text {load }}=\frac{\sum_{i=0}^{n}\left(F_{\text {load }} \times S_{i}\right)}{d \times f}
$$

...where $C_{\text {load }}$ is CCLP estimated by livestock manure nitrogen (phosphorus) load of farmland; $F_{\text {load }}$ is limited value of applying livestock manure nitrogen (phosphorus) to farmland and determined as $170 \mathrm{~kg} / \mathrm{ha}, 35 \mathrm{~kg} / \mathrm{ha}$ stipulated by EU [28, 30-31], $\mathrm{kg} / \mathrm{ha} ; S_{i}$ is cultivated land area, ha; $d$ is feeding period of pig; $f$ is excretion of nitrogen (phosphorus), $\mathrm{g} / \mathrm{d} ; n$ is number of cultivated land.

- The CCLP estimated by the alarm value of pig manure equivalent load can be calculated as follows: $[8,9]$

$$
C_{\text {alarm }}=\frac{\sum_{i=0}^{n}\left(F_{\text {suitable }} \times F_{\text {alarm }} \times S_{i}\right)}{d \times k}
$$

...where $C_{\text {alarm }}$ is CCLP estimated by the alarm value of pig manure equivalent load; $F_{\text {alarm }}$ is the alarm value of pig manure equivalent load and determined as 0.4 from previous studies [29]; $F_{\text {suitable }}$ is maximum suitable application amount of organic fertilizer as pig manure equivalent and determined as $30 \mathrm{t} / \mathrm{ha}$ from previous studies [2]; $S_{i}$ is cultivated land area, ha; $d$ is feeding period of pig; $k$ is daily excretion of pig, $\mathrm{g} / \mathrm{d} ; n$ is number of cultivated land.

\section{Results}

\section{Spatial Distribution Result of Cultivated Land in Minhou County}

The cultivated land of Minhou County in March and July, 2016 was obtained based on Landsat 8 images by using supervised classification method respectively (Fig. 1a and Fig. 1b). Then, total cultivated land area of 27665.11 ha was obtained by combining the cultivated land of Minhou County in March and July, 2016 (Fig. 1c) .

On this basis, the Compute ROI Separability in ENVI5.1 software was used to calculate the degree of sample separability to judge whether the sample was 
a)

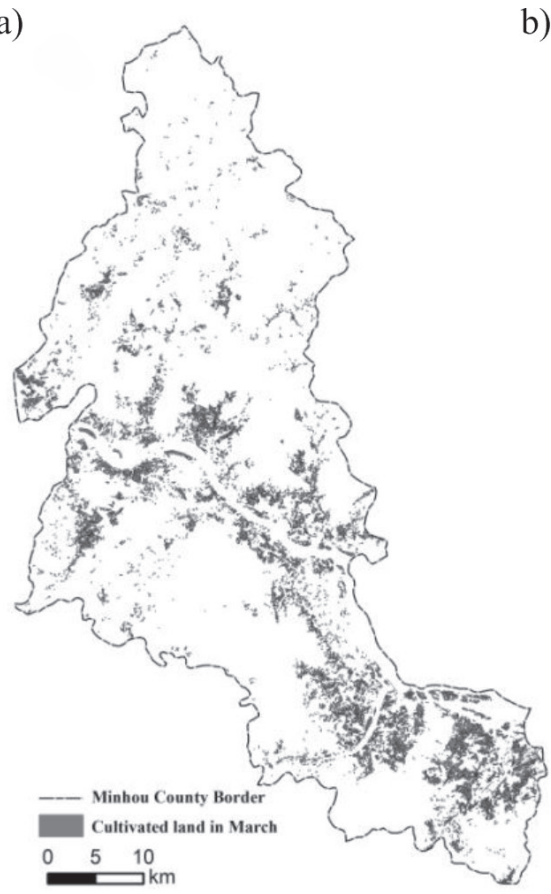

b)

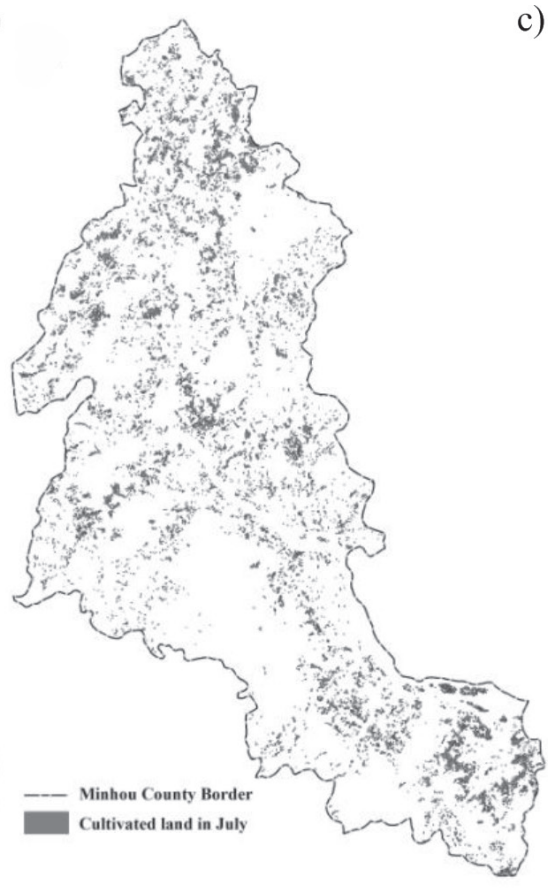

c)

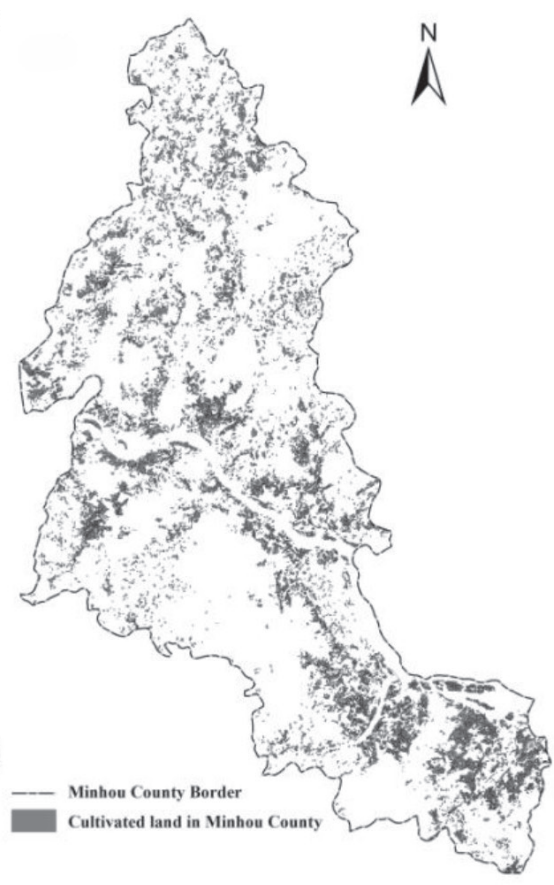

Fig. 1. Spatial distribution results of cultivated land in Minhou County in 2016.

available or not. The test result of sample separability showed that the selected samples of the regions of interest (ROI) were available (Table 1). The results also showed that the kappa coefficient and the accuracy of sample points was more than $85 \%$, which meet the accuracy requirements of the objects extraction (Table 2). According to the Yearbook of Minhou in 2017, the cultivated land area of the whole county in 2016 was 26838.00 ha. On this basis, the relative error of cultivated land area was gained as $3.08 \%$.

\section{Results of CCLP of Minhou County in Village Scale}

Based on the cultivated land area gained by 2.1, the CCLP of Minhou County in village scale in 2016 was estimated by formula (2)-(4) and GIS spatial analysis method. The results of CCLP was graded taking equivalent pig as standardized unit according to the grading standards of I and II intensive livestock and poultry farms in GB18596-2001 [32]. The different livestock and poultry types could be converted to

Table 1 . Sample separability test results.

\begin{tabular}{|c|c|c|c|c|c|c|c|}
\hline & Residential area & Woodland & Hillshade & Cultivated land & Water body & Fallow land & $\begin{array}{c}\text { Other } \\
\text { (roads, beaches) }\end{array}$ \\
\hline Residential area & $/$ & 1.99997984 & 1.99986801 & 1.99916641 & 1.99988646 & 1.99953139 & 1.85940551 \\
\hline Woodland & 1.99997984 & $/$ & 1.95645308 & 1.88285391 & 2.00000000 & 1.99999788 & 1.99999917 \\
\hline Hillshade & 1.99986801 & 1.95645308 & $/$ & 1.99972194 & 1.99996998 & 1.99999940 & 1.99999943 \\
\hline Cultivated land & 1.99916641 & 1.88285391 & 1.99972194 & $/$ & 1.99999163 & 1.99999997 & 1.99829511 \\
\hline Water body & 1.99988646 & 2.00000000 & 1.99996998 & 1.99999163 & $/$ & 2.00000000 & 1.99991536 \\
\hline $\begin{array}{c}\text { Fallow land } \\
\text { Other (roads, } \\
\text { beaches) }\end{array}$ & 1.99953139 & 1.99999788 & 1.99999940 & 1.99999997 & 2.00000000 & $/$ & 1.99999549 \\
\hline
\end{tabular}

Table 2. Accuracy of cultivated land extraction in Minhou County.

\begin{tabular}{|c|c|c|c|}
\hline Inspection method & Kappa coefficient & Sample points test & Relative error of area \\
\hline Accuracy & $92 \%($ March), $95 \%$ (July) & $88.66 \%$ & $3.08 \%$ \\
\hline
\end{tabular}




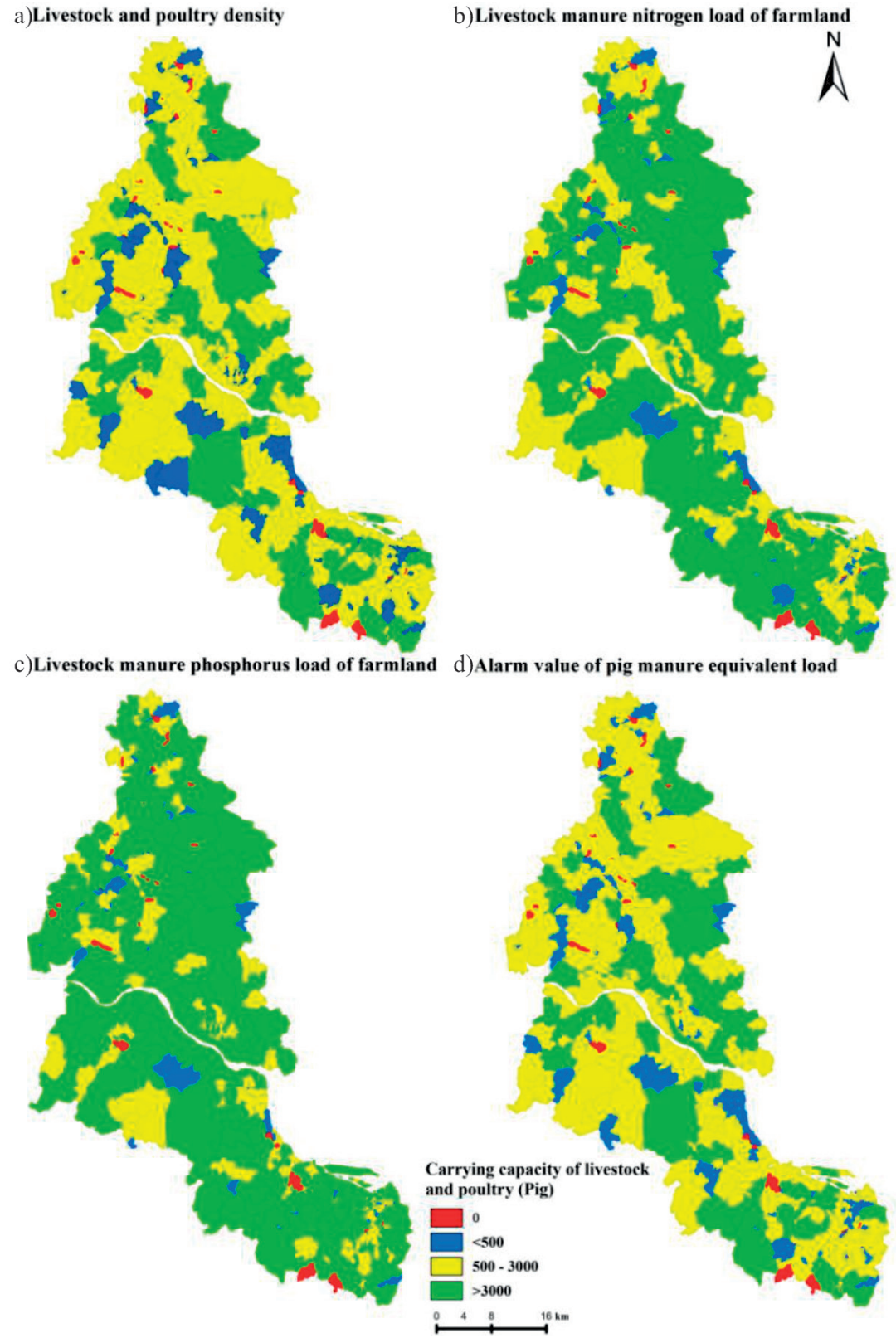

Fig. 2. Spatial distribution results of CCLP of Minhou county in village scale by 4 index.

equivalent pig according to GB18596-2001 [32]. The result was showed in Fig. 2 and Table 2.

On the whole, the spatial distribution results of CCLP of Minhou County in village scale by 4 index was uneven. The maximum CCLP was calculated by livestock manure phosphorus load of farmland, followed by livestock manure nitrogen load of farmland, alarm value of pig manure equivalent load and livestock and poultry density. Table 3 indicated that the CCLP calculated by livestock and poultry density

Table 3. Statistical result of CCLP of Minhou County in village scale by 4 index.

\begin{tabular}{|c|c|c|c|c|}
\hline Index & Total number & Maximum number & Minimum number & Average number \\
\hline Livestock and poultry density (AU/ha) & 618415.862 & 6775.779 & 9.237 & 1569.583 \\
\hline $\begin{array}{c}\text { Livestock manure nitrogen load of } \\
\text { farmland(kg/ha) }\end{array}$ & 1399765.346 & 15336.767 & 20.909 & 3552.704 \\
\hline $\begin{array}{c}\text { Livestock manure phosphorus load of } \\
\text { farmland(kg/ha) }\end{array}$ & 2274814.360 & 24924.391 & 33.980 & 5773.641 \\
\hline Alarm value of pig manure equivalent load & 690650.709 & 7567.232 & 10.317 & 1752.921 \\
\hline
\end{tabular}


was close to the CCLP calculated by the alarm value of pig manure equivalent load. However, the CCLP calculated by livestock manure phosphorus load of farmland was about 3.678 times of the CCLP calculated by the livestock and poultry density. In addition, the largest number of villages with CCLP more than 3000 pigs was 211 by livestock manure phosphorus load of farmland, followed by 147 by livestock manure nitrogen load of farmland, and the smallest number of villages with CCLP more than 3000 pigs was 45 by livestock and poultry density.

The largest number of villages with CCLP between 500 and 3000 pigs was 213 by livestock and poultry density, followed was 210 by the alarm value of pig manure equivalent load, and the smallest number of villages with CCLP between 500 and 3000 pigs was 92 by livestock manure phosphorus load of farmland. Moreover, the largest number of villages with CCLP less than 500 pigs was 71 by livestock and poultry density, followed by 65 by the alarm value of pig manure equivalent load, and the smallest number of villages with CCLP less than 500 pigs was 26 by livestock manure phosphorus load of farmland. In summary, the CCLP calculated by 4 index was very different. However, the maximum and minimum value of CCLP calculated by 4 index was all in Xitou village and Houcun village in Baisha Town respectively.

In view of environmental pollution safety of LPB, the CCLP calculated by livestock and poultry density was the most stringent, followed by the CCLP calculated by alarm value of pig manure equivalent load. The CCLP calculated by livestock manure phosphorus load of farmland was least stringent. Therefore, to reduce environmental pollution risk from LPB and keep sustainable development of LPB, the livestock and poultry density should be selected to calculate CCLP. However, livestock manure phosphorus load of farmland might be selected to calculate livestock manure phosphorus load of farmland in view of developing local economy and increasing the income of farmers.

\section{Discussion and Conclusions}

The cultivated land of Minhou County was obtained by RS technology based on Landsat 8 images. On this basis, the CCLP in Minhou County in village scale was calculated by indexes including livestock and poultry density, livestock manure nitrogen (phosphorus) load of farmland, and the alarm value of pig manure equivalent load. At present, the cultivated land extracted based on Landsat TM data by using RS technology has been adopted by many researchers [19-21]. In addition, the status of cultivated land might change in different seasons leading to the differences in remote sensing images of the reflectivity of cultivated land. Therefore, the cultivated land was obtained based on multitemporal remote sensing image would be more accurate than the cultivated land obtained based on singletemporal remote sensing image [33-34]. According to main crops and its planting area in Minhou County, the time for planting crops was generally in March or April [35], and the peak period for growing crops was generally in July [36]. Therefore, the result of cultivated land of Minhou County was gained by merging cultivated land of Minhou County in March and July, 2016.

Comparing with previous studies estimating administrative scale such as national scale, province scale, city scale, county scale and town scale [4-9,1214], this paper calculated CCLP in village scale and compared the CCLP calculated by 4 index. The results indicated that the most stringent index was livestock and poultry density, followed by the alarm value of pig manure equivalent load and least stringent index was livestock manure phosphorus load of farmland. In view of regional environmental pollution safety of LPB, this result was basically consistent with the results from Yan et al. [37]. The results in this paper was significant to control regional CCLP and arrange reasonable LPB in village scale. Thus, the environmental pollution risk from LPB might be reduced and LPB could kept sustainable development. Moreover, the result could provide scientific reference for determining forbidden region, restricted region and suitable region for LPB.

In addition, there were still some problems to be improved in the future. Firstly, the actual number of livestock and poultry in villages in Minhou County was not be analyzed due to the lack of statistical data of livestock and poultry in villages. Secondly, there inevitable errors in estimating cultivated land area because the maximum resolution of Landsat 8 image was only $15 \mathrm{~m}$. In the future, higher resolution images and better classification methods should be used to estimate cultivated land area.

\section{Acknowledgements}

This research had been partly supported by the National Natural Science Foundation of China under Grant No.41601601, 61971236, 61501249, the New Century Excellent Researcher Award Program from Fujian Province under Grant No.3230412301, and the Project funded by China Postdoctoral Science Foundation under Grant No.2018M632348.

\section{Conflict of Interest}

The authors declare no conflict of interest.

\section{References}

1. WU L.F., OUYANG Z., XIE X.L. Carrying capacity of livestock in cropland of two typical regions dominated by 
agriculture in China.Journal of Natural Resources, 28 (1), 104, 2013.

2. ZHU J.C., ZHANG Z.Q., FAN Z.M., LI R.H. Biogas potential, cropland load and total amount control of animal manure in China. Journal of Agro-Environment Science, 33 (3), 435, 2014.

3. PAN D. Environment carrying capacity and pollution risk of livestock breeding in ecological economic zone of Poyang lake. Bulletin of Soil \& Water Conservation, 36 (2), 254, 2016.

4. TAMMINGA S. Pollution due to nutrient losses and its control in European animal production. Livestock Production Science, 84 (2), 101, 2003.

5. YU M., ELLIS J.E., EPSTEIN H.E. Regional analysis of climate, primary production, and livestock density in Inner Mongolia.Journal of Environmental Quality, 33 (5), 1675, 2004.

6. GENG W., HU L., CUI J.Y., BU M.D., ZHANG B.B. Biogas energy potential for livestock manure and gross control of animal feeding in region level of China. Transactions of the Chinese Society of Agricultural Engineering, 29 (1), 171, 2013.

7. YANG Q., TIAN H., LI X., REN W., WOLF J. Spatiotemporal patterns of livestock manure nutrient production in the conterminous united states from 1930 to 2012. Science of The Total Environment, 541 (4), 1592, 2016.

8. PAN Y.C., SUN C., LIU Y., TANG X.M., REN Y.M. Carrying capacity of livestock and poultry breeding based on feces disposal volume of land. Transactions of the Chinese Society of Agricultural Engineering, 31 (4), 232, 2015.

9. YAN B., YAN J., SHI W. Estimation of carrying capacity of livestock farm based on maximum phosphorus load of farmland and GIS spatial analysis technology. Current Science, 112 (9), 1931, 2017.

10. LIU Z., DUAN Z.Q. Distribution of Manure Resources and Environmental Loads of Agro-ecological Regions in China. Resources Science, 32 (5), 946, 2010.

11. YI X., YE L.F., LIU Y.Z., TIAN L.H., CHEN S.J. Estimations of livestock manure load and risk assessment of environmental tolerance in Shanxi Province. Agricultural research in the arid areas, 33 (3), 205, 2015.

12. FAJJI N.G., PALAMULENI L.G., MLAMBO V. A GIS Scheme for Forage Assessment and Determination of Rangeland Carrying Capacity. Journal of Remote Sensing \& GIS, 7 (1), 1, 2018.

13. IRIANY A., MULYANTO A., MASHUDI M., MAYLINDA S. Analysis of feed carrying capacity for ruminant livestock in Madura Island, Indonesia. Journal of Rangeland Science, 9 (3), 313, 2019.

14. THAPA G.B., PAUDEL G.S. Evaluation of the livestock carrying capacity of land resources in the Hills of Nepal based on total digestive nutrient analysis. Agriculture, Ecosystems \& Environment, 78 (3), 223, 2000.

15. WU L.F., OUYANG Z. Regional livestock density under environmental capacity based on nitrogen and phosphorus budget of farmland: a case study of Yucheng county in Shandong province. Journal of Agro-Environment Science, 28 (11), 2277, 2009.

16. PENG L., BAI Y. Numerical study of regional environmental carrying capacity for livestock and poultry farming based on planting-breeding balance.Journal of Environmental Sciences, 25 (9), 1882, 2013.

17. HAO X.Y., TANG X.M., PAN Y.C., LIU Y., REN Y.M., ZHANG Y.P., QIU H. Optimization and implementation of livestock and poultry breeding configuration: taking land consolidation project in Yaoshan and Gaoyupu towns of Shunping county, Hebei province as study case. Acta Scientiarum Naturalium Universitatis Pekinensis, 51 (5), 923, 2015.

18. XU Y., YU L., ZHAO Y., FENG D., CHENG Y., CAI X., GONG P. Monitoring cropland changes along the Nile River in Egypt over past three decades (1984-2015) using remote sensing. International Journal of Remote Sensing, 38 (15), 4459, 2017.

19. KHAN A., KHATTAK S., WALEED M., KHAN A., KHAN U. On the application of remote sensing towards the estimation of cultivated land lost to urbanization. The Imaging Science Journal, 67 (5), 254, 2019.

20. MEKURIAW A., HEINIMANN A., ZELEKE G., HURNI H., HURNI K. An automated method for mapping physical soil and water conservation structures on cultivated land using GIS and remote sensing techniques. Journal of geographical sciences, 27 (1), 79, 2017.

21. ZHANG C.H., LI X.N., WU M.Q., QIN W.H. Objectoriented Classification of Land Cover Based on Landsat 8 OLI Image Data in the Kunyu Mountain. Scientia Geographica Sinica, 38 (11), 1904, 2018.

22. JIA K., LI Q.Z., TIAN Y.C., WU B.F. A review of classification methods of remote sensing imagery. Spectroscopy and Spectral Analysis, 31 (10), 2618, 2011.

23. JING R., DENG L., ZHAO W.J., GONG Z.N. Objectoriented aquatic vegetation extracting approach based on visible vegetation indices. Chinese Journal of Applied Ecology, 27 (5), 1427, 2016.

24. CHEN X.L., ZHAN S.Introduction to remote sensing digital image processing.Beijing: China Machine Press, 2007.

25. ZHAO J., LIU L., ZHANG Y., WANG X., WU F. A novel way to rapidly monitor microplastics in soil by hyperspectral imaging technology and chemometrics. Environmental Pollution, 238, 121, 2018.

26. HAN X., PAN J., DEVLIN A.T. Remote sensing study of wetlands in the Pearl River Delta during 1995-2015 with the support vector machine method. Frontiers of Earth Science, 12 (3), 521, 2018.

27. WU S.R., CHEN Z.X., REN J.Q., ZHOU Q.B., HUANG Q. Influence of mapping scales and pixel spatial relationships on GF-1 sub-pixel mapping accuracy. Transactions of the Chinese Society of Agricultural Engineerin, 32 (5), 163, 2016.

28. FENG A., WANG X., LIU Z. Temporal-spatial analysis of environmental risks from animal production in northeast china. Research of Environmental Sciences, 28 (6), 967, 2015.

29. MENG C., LI Y.Y., XU X.G., GAO R., WANG Y., ZHANG M.Y., WU J.S. A case study on non-point source pollution and environmental carrying capacity of animal raising industry in subtropical watershed. Acta Scientiae Circumstantiae, 33 (2), 635, 2013.

30. SCHRODER J.J., AARTS H.F.M., BERGE H.F.M.T., KEULEN H.V., NEETESON J.J. An evaluation of wholefarm nitrogen balances and related indices for efficient nitrogen use. European Journal of Agronomy, 20 (1-2), 33, 2003.

31. ULÉN B., BECHMANN M., FÖLSTER J., JARVIE H.P., TUNNEY H. Agriculture as a phosphorus source for eutrophication in the north-west European countries, norway, sweden, united kingdom and ireland: a review. Soil Use and Management, 23 (s1), 5, 2007. 
32. GB18596-2001. Discharge standard of pollutants for livestock and poultry breeding, 2001.

33. XIAO X., BOLES S., FROLKING S., LI C., BABU J.Y., SALAS W., MOORE III B. Mapping paddy rice agriculture in South and Southeast Asia using multi-temporal MODIS images. Remote Sensing of Environment, 100 (1), 95, 2006.

34. XU C., ZHAN J.R., PAN Y.Z., ZHU W.Q. Extraction of cropland information based on multi-temporal TM images. Remote Sensing for Land and Resources, 25 (4), 166, 2013.
35. LU T.T., LIU C. Spatio-temporal distributions of multiple cropping systems in the pearl river delta of China and four deltas in southeast Asia. Resources Science, 31 (10), 1662, 2009.

36. LIU H., YU S., ZHANG X., GUO D., YIN J. Timeliness analysis of crop remote sensing classification one crop a year. Scientia Agricultura Sinica, 50 (5), 830, 2017.

37. YAN B.J., YAN J.J. Comparative Analysis of Characterization Methods of Potential Environmental Pollution Risk from Livestock and Poultry Breeding. Polish Journal of Enviromental Studies, 28 (4), 2483, 2019. 